\title{
Distributed MPP Tracking of PV through Buck Converter Using Fuzzy
}

\author{
Chandani Sharma*, Anamika Jain \\ Department of Electronics and Communication Engineering, Graphic Era University, Dehradun, India \\ ${ }^{*}$ Corresponding author, e-mail: chandani19nov@gmail.com
}

\begin{abstract}
Photovoltaics (PV) are the most abundant, perennial, environment friendly and distributed source of energy all over the globe. In this paper, the method to increase PV extraction efficiency for 60W panel with improved DMPP (Distributed Maximum Power Point) even on changing temperature and irradiance have been mapped and discussed. In order to achieve this, the components and subsystems have been analyzed and validated. The validated models are used to maximize the power output using two different models of DC-DC Converters in MATLAB/SIMULINK environment. Closed loop Buck converter using state space nonlinear differential equations and direct component model are compared to reveal best results at Standard Test Conditions (STC). MPPT model developed can be used for obtaining maximum power output from PV even in partial presence of sun using Fuzzy Logic Controller. The Controller designed tracks highest power output for the buck converter. The model developed, using tested membership functions in FLC, can serve a platform for various real time applications using PV.
\end{abstract}

Keywords: Photovoltaics, MATLAB/SIMULINK, Buck converter, STC

Copyright $\odot 2015$ Institute of Advanced Engineering and Science. All rights reserved.

\section{Introduction}

Solar energy maintains all life on earth. Solar is an emerging sustainable technology with immense potential to contribute largest investment in Green technology applications. Due to shortage and environmental impact of conventional fuels, solar powered systems assume importance to overcome hurdles and promote economic advantages. Easy implementation and design demands in electricity sector are making PV use significant in electricity generation and distribution purposes. Globally 1.5 billion people with no access to electricity can be developed through widespread adoption in PV innovative business [1].

PV modules are constructed using solar cells. Solar cells work on photoelectric effect converting sunlight into electricity. Since the output available from single solar cell is very small, series or parallel combination is preferred to obtain higher output from panel. Even under changing environmental conditions, efficiency of panel needs to be streamlined. For this, solar panel is under distributed conditions need to be operated at MPP (maximum power point). MPP describes a fixed operating point on IV (Current-Voltage) and PV (Power-Voltage) characteristic curves of solar cell. STC (standard test conditions) are desired with temperature of $25{ }^{\circ} \mathrm{C}$ (298.15K) and an irradiance of $1000 \mathrm{~W} / \mathrm{m}^{2}$ to maintain MPP in all cases [2].

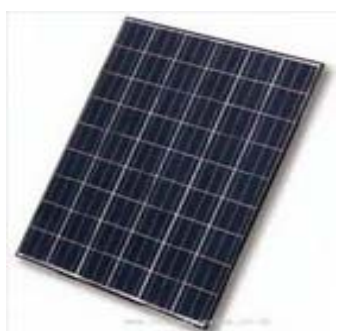

(a)

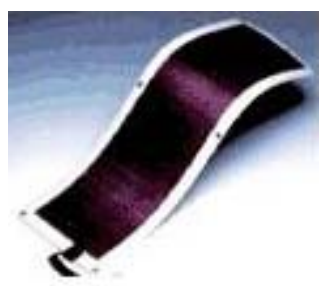

(b)

Figure 1. PV panel structures; (a) Crystalline, (b) Thin Film 
To obtain MPP in distributed conditions of changing temperature and irradiance, MPPT is designed. PV panels available in market include Crystalline (mono or poly) and Thin Film structures. The advantages of using fixed crystalline panels are that they use chemical silicon while thin film structures use amorphous silicon based on vapour deposition. Figure 1 shows both panel structures.

\section{Research Method}

In this research paper, firstly a systematic analysis of solar panel module based on mathematical modeling in Simulink-MATLAB is performed [3]. Thereafter, its investigation is performed for variable temperature and irradiance. MPP is successfully obtained [4]. The MPP tracking system for changing conditions is implemented using DC/DC Buck Converter followed by an FLC to monitor output of Converter. An estimation of two different models of buck converter is done using different temperature and irradiance conditions.

PV panel modeling for solar cells was done in SIMULINK-MATLAB using solar panel equations expressed as:

Thermal Voltage Equation

$\mathrm{V}_{\mathrm{T}}=\mathrm{k}_{\mathrm{B}} \mathrm{T}_{\mathrm{OPT}} / \mathrm{q}$

Diode Current Equation

$I_{D}=N_{p} I_{S}\left[e^{(V / N s)+(I R s / N s) / N V_{T} C}-1\right]$

Load Current Equation

$I_{L}=I_{P h} N_{P}-I_{D}-I_{S H}$

Photocurrent Equation

$I_{p h}=\left[k_{i}\left(T_{O P T}-T_{R E F}\right)+I_{S C}\right] I_{R R}$

Shunt Current Equation

$I_{S H}=\left(I R_{S}+V\right) / R_{S H}$

Reverse Saturation Current

$I_{S}=\left[I_{R S}\left(T_{O P T} / T_{R E F}\right)^{3 *} q^{2} E g / N k_{B}{ }^{*} e^{(1 / T}{ }_{O P T}{ }^{-1 / T}{ }_{R E F}\right)$

Reverse Current Equation

$I_{R S}=I_{S C} /\left[e^{(q \vee} V_{O C} i^{l k C T}\right.$ OPT -1$]$

Output Power

$\mathrm{P}=\mathrm{VI}$

Where,

\begin{tabular}{ll} 
Table & 1. Terminology for constructing solar panel \\
\hline$V_{T}$ & Thermal Voltage \\
$V$ & Operating Voltage \\
$V_{O C}$ & Open ckt voltage \\
$I_{S C}$ & Short circuit current \\
$I_{S}$ & Reverse Saturation Current of Diode \\
$I_{\text {ph }}$ & Photocurrent \\
$I$ & Cell Output Current \\
$T_{R E F}$ & Reference Temperature of cell \\
$T_{O P T}$ & Operating Temperature \\
$\mathrm{R}_{S H}$ & Shunt Resistance of Cell \\
$R_{S}$ & Series Resistance of Cell \\
$E g$ & Energy Band Gap \\
$N$ & Ideality Factor \\
$k B$ & Boltzmann constant \\
$k i$ & Current Proportionality constant \\
$q$ & Electron charge \\
$G$ & Irradiance \\
Ns & No. of cells in series \\
$C$ & No. of Cells in module \\
\hline
\end{tabular}

TELKOMNIKA Vol. 15, No. 2, August 2015: $197-208$ 
Solar panel modeled is tested for STC with specifications given below,

Table 2. Specifications of model

\begin{tabular}{cc}
\hline \multicolumn{2}{c}{$\begin{array}{c}\text { Characteristics at STC with } \\
\mathrm{G}=1 \mathrm{KW} / \mathrm{m}^{2} \text { and } \mathrm{T}=25^{\circ} \mathrm{C}\end{array}$} \\
\hline $\mathrm{P}_{\mathrm{MPP}}$ & $59.39 \mathrm{~W}$ \\
$\mathrm{~V}_{\mathrm{MP}}$ & $16.64 \mathrm{~V}$ \\
$\mathrm{I}_{\mathrm{MP}}$ & $3.567 \mathrm{~A}$ \\
$\mathrm{I}_{\mathrm{SC}}$ & $3.7981 \mathrm{~A}$ \\
$\mathrm{~V}_{\mathrm{OC}}$ & $21.07 \mathrm{~V}$ \\
\hline
\end{tabular}

Figure 2 shows complete subsystem designed.

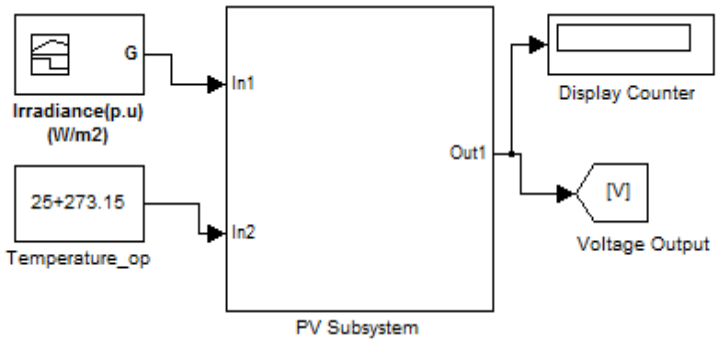

Figure 2. Solar Panel Subsystem

When model is simulated in MATLAB, Simout values available at PV subsystem output appear as shown in Table 3 for variable temperature and Table 4 for variable irradiance.

Table 3. Simout variables for changing Temperature

\begin{tabular}{llllll}
\hline $\mathrm{T}^{\circ} \mathrm{C}$ & $\mathrm{V}_{\mathrm{OC}}$ & $\mathrm{I}_{\mathrm{SC}}$ & $\mathrm{V}_{\mathrm{MPP}}$ & $\mathrm{I}_{\mathrm{MPP}}$ & $\mathrm{P}_{\mathrm{MPP}}$ \\
\hline 5 & 21.31 & 3.754 & 18.06 & 3.317 & 59.92 \\
10 & 21.25 & 3.765 & 16.69 & 3.578 & 59.75 \\
15 & 21.19 & 3.776 & 16.68 & 3.575 & 59.65 \\
20 & 21.13 & 3.787 & 16.66 & 3.571 & 59.53 \\
25 & 21.07 & 3.798 & 16.64 & 3.567 & 59.39 \\
30 & 21.01 & 3.809 & 16.62 & 3.563 & 59.23 \\
35 & 20.95 & 3.820 & 16.60 & 3.557 & 59.06 \\
40 & 20.89 & 3.831 & 16.57 & 3.552 & 58.87 \\
45 & 20.83 & 3.842 & 16.54 & 3.545 & 58.67 \\
\hline
\end{tabular}

Table 4. Simout variable for changing Irradiance

\begin{tabular}{cccccc}
\hline Irradiance & $\mathrm{V}_{\mathrm{OC}}$ & $\mathrm{I}_{\mathrm{SC}}$ & $\mathrm{V}_{\mathrm{MPP}}$ & $\mathrm{I}_{\mathrm{MPP}}$ & $\mathrm{P}_{\mathrm{MPP}}$ \\
\hline Step & 20.41 & 2.278 & 16.40 & 2.109 & 34.61 \\
Constant & 21.07 & 3.798 & 16.64 & 3.567 & 59.39 \\
Trapezoidal & 20.78 & 3.038 & 17.12 & 2.752 & 47.12 \\
\hline
\end{tabular}

The experiment highlights that reading of Open circuit voltage $V_{O C}$ and Short circuit current $I_{\mathrm{SC}}$ are more sensitive to irradiance variations as compared to temperature. The Open circuit voltage $V_{O C}$ decreases sharply with increase in Short circuit current $I_{S C}$.

The characteristic curves obtained from Simout are shown in Figure 3. 


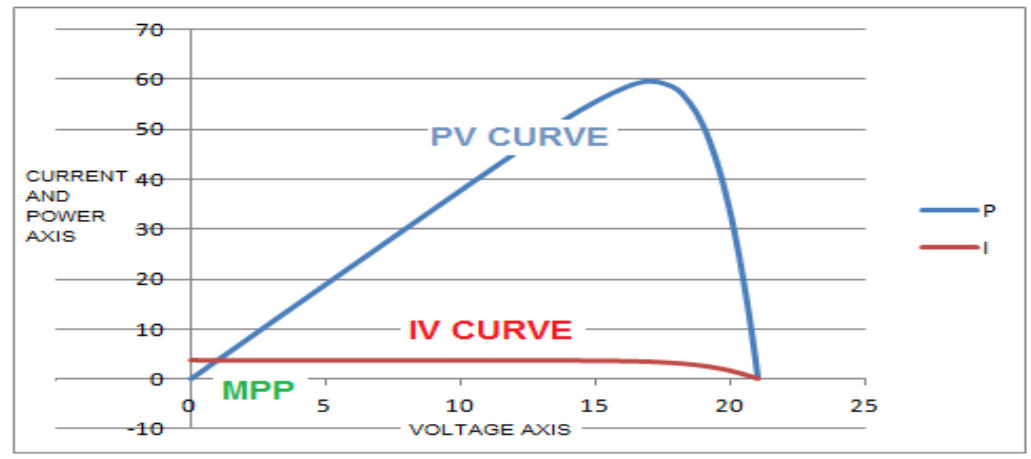

Figure 3. IV and PV Characteristic curves

The characteristics of panel vary in accordance with varying temperature and irradiance when its output is obtained across a resistive load. The change observed is given by Dynamic Impedance of source given by expression:

$$
\frac{d V}{d I}=-\frac{V}{I}
$$

Thus, to monitor MPP in distributed conditions, MPPT is modeled as in Figure 4, using Buck Converter.

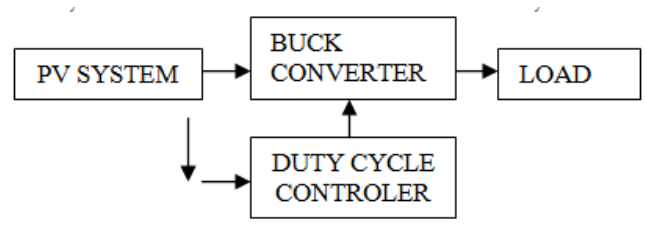

Figure 4. Blocks used in MPP Tracker circuit

\section{Design Of Buck Converter}

The output current, voltage or power characteristics of PV panel vary across load with change in temperature and irradiance. However, reduced and mismatch power output can be compensated by use of Converters and Controllers $[5,6]$. Buck converters are used to decrease voltage at output. Basically, components used include MOSFET, diode, and inductor followed by filter capacitor and load at output. A control circuit is used to determine for how much voltage is required across load by converter using controller set point. For this, MOSFET is switched ON and OFF by Controller pulses on Gate. Figure 5 shows Buck converter.

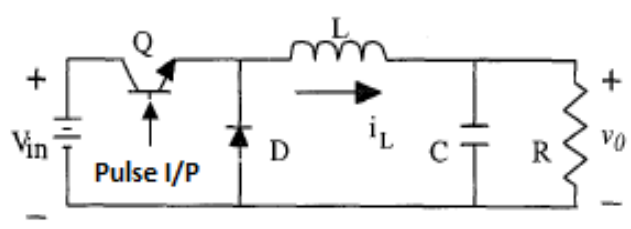

Figure 5. Basic circuit of Buck converter

The pulses obtained at Gate of MOSFET depict converter operating frequency. A variation in converter operating frequency changes duty cycle of converter. Duty cycle is defined operation for which circuit works in ON state to duration for which it is ON and OFF. Two 
different models are studied based on state space model equations and use of direct components available in MATLAB-SIMULINK. These are described below.

\subsection{Model-A}

State space model is determined considering binary values of inductor and capacitor. Discrete or continuous GUI model is selected. MOSFET is categorized as ON and OFF based on operational input pulse at gate. With this when MOSFET is considered ON, inductor current $\mathrm{i}_{\mathrm{L}}(\mathrm{t})$ and the capacitor voltage $\mathrm{v}_{\mathrm{C}}(\mathrm{t})$ appear:

$$
\left\{\begin{array}{l}
\frac{d i_{L}}{d t}=\frac{1}{L}\left(V_{i n}-v_{o}\right) \\
\frac{d v_{o}}{d t}=\frac{1}{C}\left(i_{L}-\frac{v_{o}}{R}\right)
\end{array}, \quad 0<t<d T, \quad Q: O N\right.
$$

And when the switch is OFF are presented by:

$$
\left\{\begin{array}{l}
\frac{d i_{L}}{d t}=\frac{1}{L}\left(-v_{o}\right) \\
\frac{d v_{o}}{d t}=\frac{1}{C}\left(i_{L}-\frac{v_{o}}{R}\right)
\end{array}, \quad d T<t<T, \quad Q: O F F\right.
$$

Using above equations, model is constructed as in Figure 6.

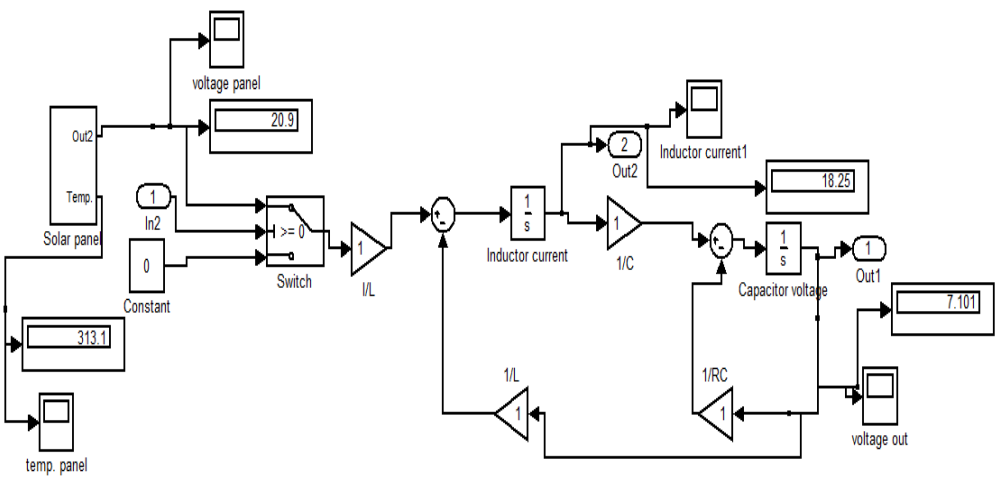

Figure 6. Buck Converter using state space variables

\subsection{Model-B}

Instead of using ON and OFF variables, this model uses direct components to determine output using pulse generator at gate. Figure 7 and Figure 8 shows modeling of Buck Converter with and without control pulse generator.

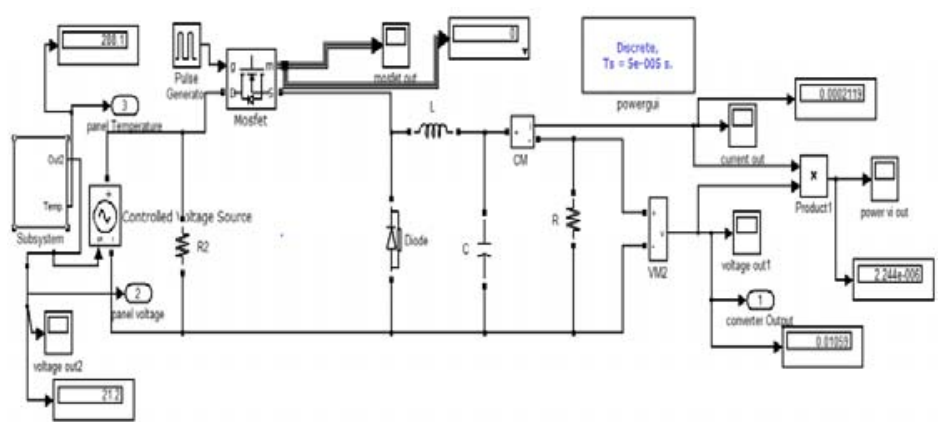

Figure 7. Buck Converter using Pulse Generator at gate 


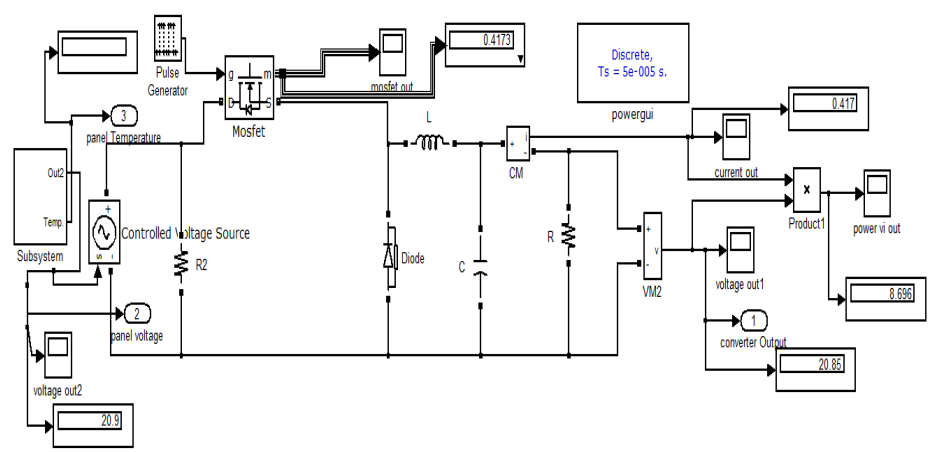

Figure 8. Buck Converter using controlled Pulse Generator at gate

Based on models discussed above, comparison is framed prior to outputs obtained across Converter 1, 2 and 3 for variable temperature and irradiance.

\subsection{Variable Temperature}

The measurements for variable temperature are expressed using three models of Buck Converter in Table 5. $\mathrm{V}$ conv shows control function using Controller to obtain voltage stabilization. $V$ conv1 uses steady space model output followed by $V$ conv2 that uses normal pulse given from Pulse Generator. Here irradiance $G$ is kept constant at $1000 \mathrm{~W} / \mathrm{m}^{2}$.

\begin{tabular}{cllll}
\multicolumn{5}{c}{ Table 5. Simout Readings using Buck converter for $\mathrm{T}^{\circ} \mathrm{C}$} \\
\cline { 1 - 5 } $\mathrm{T}{ }^{\circ} \mathrm{C}$ & $\begin{array}{l}\mathrm{V}_{\text {oc }} \\
\text { desired }\end{array}$ & $\begin{array}{l}\mathrm{V}_{\text {conv }} \\
\text { With } \\
\text { Controller }\end{array}$ & $\begin{array}{l}\mathrm{V}_{\text {conv } 1} \\
\text { With state } \\
\text { space }\end{array}$ & $\begin{array}{l}\mathrm{V}_{\text {conv2 }} \\
\text { With Pulse } \\
\text { Generator }\end{array}$ \\
\hline 5 & 21.31 & 21.27 & 7.243 & .01065 \\
10 & 21.25 & 21.25 & 7.223 & .01062 \\
15 & 21.19 & 21.20 & 7.204 & .01059 \\
20 & 21.13 & 21.14 & 7.184 & .01056 \\
25 & 21.07 & 21.08 & 7.164 & .01053 \\
30 & 21.01 & 21.02 & 7.143 & .01050 \\
35 & 20.95 & 20.96 & 7.122 & .01047 \\
40 & 20.89 & 20.90 & 7.101 & .01044 \\
45 & 20.83 & 20.83 & 7.08 & .01041 \\
\hline
\end{tabular}

\subsection{Variable Irradiance}

To show variation of irradiance $G$, the models are analyzed for three different irradiance functions with constant temperature at $25^{\circ} \mathrm{C}$. These are step, constant and trapezoidal types. Table 6 lists values of Model A and B for three different irradiance types.

Table 6. Panel and Converter output for variable temperature and Irradiance $\mathrm{G}$

\begin{tabular}{cllll}
\hline $\mathrm{T}^{\circ} \mathrm{C}$ & $\mathrm{V}_{\text {Conv }}$ & \multicolumn{2}{l}{$\begin{array}{l}\text { Converter output } \\
\left(\mathrm{V}_{\text {Conv } 1 \text { and }} \mathrm{V}_{\text {Conv2 }}\right)\end{array}$} \\
& & Constant $\mathrm{G}$ & Step G & Trapezoidal G \\
\hline 15 & 21.20 & 0.01082 & 0.01078 & 0.01080 \\
20 & 21.14 & 0.01086 & 0.01082 & 0.01084 \\
25 & 21.08 & 0.01092 & 0.01088 & 0.01090 \\
30 & 21.02 & 0.01098 & 0.01094 & 0.01092 \\
\hline
\end{tabular}

\subsection{Variable Temperature and Irradiance}

Since changing temperature and irradiance parameters manually is time consuming, automatic tune block is introduced. On modeling variable block by Simulink for temperature and irradiance panel gives Table 7 . 
Table 7. Panel output for variable temperature and Irradiance G

\begin{tabular}{lll}
\hline $\mathrm{T}^{\circ} \mathrm{C}$ & Fixed Model & Variable model \\
\hline 15 & 21.19 & 21.57 \\
20 & 21.13 & 21.77 \\
25 & 21.07 & 21.86 \\
30 & 21.01 & 21.95 \\
\hline
\end{tabular}

Thus, to trace out fittest solution for MPP, voltage needs to be stabilized for results closer to STC. Thus Model B giving superior results over A is used for set point tracking. The implementation of controllers improves performance of Buck Converter. Design and implementation of FLC is described below.

\section{Fuzzy Logic Controller}

A Controller is used to establish control functions for converter to monitor desired current, voltage or power at output of panel. Figure 9 shows basic block diagram using Controller, PV and Converter subsystem.

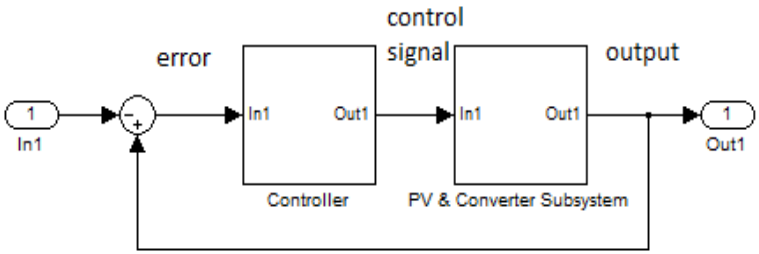

Figure 9. Block diagram of Controller

A fuzzy system is a knowledge-based system which utilizes fuzzy if-then rules and fuzzy logic in order to obtain the output of the system. The Fuzzy logic controller used adjusts the converter duty cycle. FLC can be easily tuned and efficiently used to monitor voltage output from panel even under time varying processes $[7,8]$. The desired output is obtained by varying the design parameters as each membership function for temperature, voltage and duty cycle. The different processes in obtaining controlled outputs from FLC are given in Figure 10.

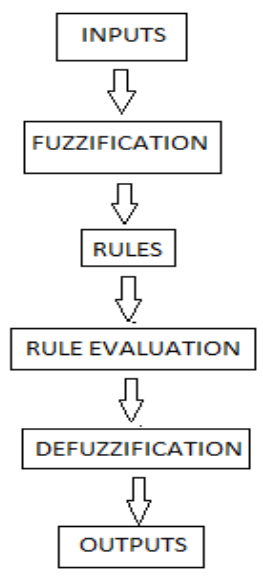

Figure 10. Processes used in FLC

A two-input single-output fuzzy logic controller is designed with the input variables as: the error $(E)$ and change in error $(\Delta E)$ scaled for voltage given by Equation (12) and (13). 
$E(n)=\frac{P(n)-P(n-1)}{I(n)-I(n-1)}$

$\Delta E(n)=E(n)-E(n-1)$

The output variable is duty cycle (D) of the converter given by Equation (14).

$$
\mathrm{D}=\frac{\text { Vout }}{\text { Vin }}
$$

Various process used in designing of FLC are described as follows.

a) Process of Fuzzification: The input variables in a fuzzy control system are mapped into sets of membership functions termed "fuzzy sets". The process, of converting a crisp input value to a fuzzy value, is called "fuzzification". The input-output variables used, are given in Figure 11.

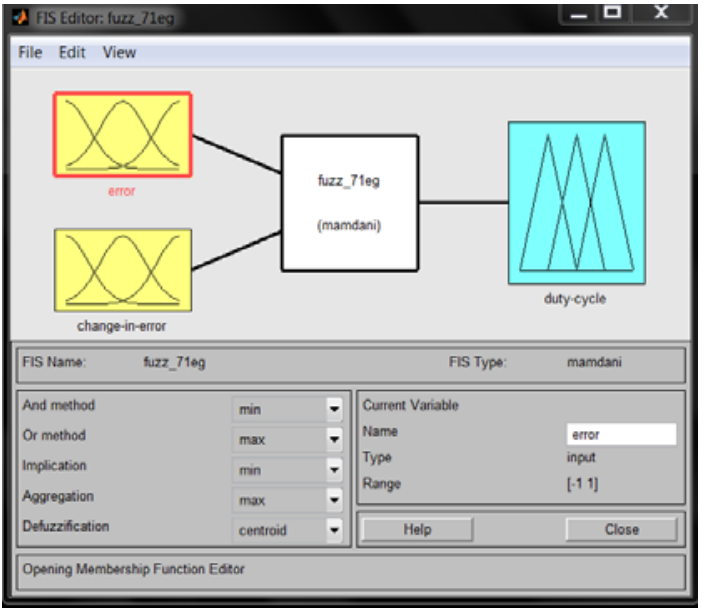

Figure 11. Input-Output variables of the FLC

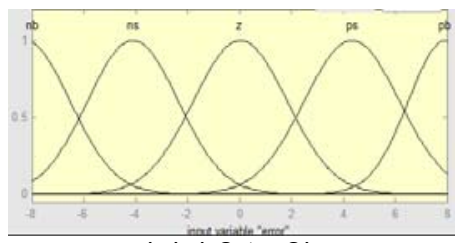

(a) $(-8$ to 8$)$

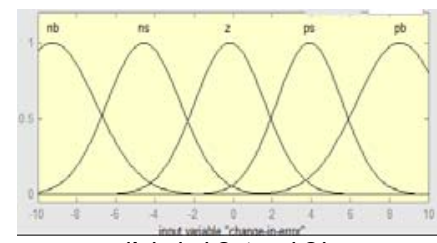

(b) $(-10$ to 10$)$

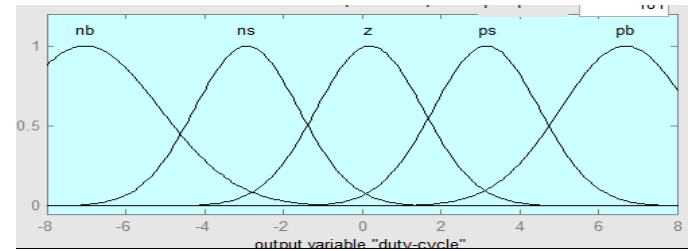

(c) $(-8$ to 8$)$

Figure 12. Membership functions (a) Error Input (E) (b) change in error $(\Delta E)$ and (c) Output (D)

The input voltage values are scaled and normalized into values closer to $21.07 \mathrm{~V}$. Through the membership function, the related fuzzy values $(0 \sim 1)$ can be estimated for each 
fuzzy descriptor: NB, NS, Z, PS, and PB namely, NB negative big, NS negative small, Z zero, PS positive small and PB positive big. Gaussian membership functions with 0.5 crossovers are used as they appear smooth and non-zero at all points providing less overshoot and undershoot with faster Rise time. These are shown in Figure 12.

The "mappings" of input variables into membership functions and truth values help the controller to make decisions for what action is to be taken based on a set of "rules".

b) Fuzzy Rules: The distinguishing mark of Fuzzy Logic in "rule-based". The rule base implements the expert knowledge in a form of IF-THEN rule structure.

Table 8 shows the fuzzy logic rules formulated.

\begin{tabular}{llllll}
\multicolumn{5}{c}{ Table 8. Fuzzy Rules } \\
\hline \multicolumn{1}{c}{$\Delta \mathrm{E}$} & NB & NS & Z & PS & PB \\
E & & & & & \\
\hline NB & Z & Z & NB & NB & NB \\
NS & Z & Z & NS & NS & NS \\
Z & NS & Z & Z & Z & PS \\
PS & PS & PS & PS & Z & Z \\
PB & PB & PB & PB & Z & Z \\
\hline
\end{tabular}

The $5 \times 5$-rule matrix may be redefined in 25 rules:

If $E(n)$ is $N B$ and $\triangle E(n) N B$, then $D$ is $Z$.

If $E(n)$ is NB and $\Delta E(n) N S$, then $D$ is $Z$.

If $E(n)$ is NB and $\Delta E(n) Z$, then $D$ is NB.

If $E(n)$ is $N B$ and $\triangle E$ (n) PS, then $D$ is NB.

If $E(n)$ is $N B$ and $\triangle E(n) P B$, then $D$ is NB.

If $E(n)$ is $N S$ and $\Delta E(n) N B$, then $D$ is $Z$.

If $E(n)$ is NS and $\Delta E(n) N S$, then $D$ is $Z$.

If $E(n)$ is NS and $\Delta E(n) Z$, then $D$ is NS.

If $E(n)$ is NS and $\triangle E(n) P S$, then $D$ is NS.

If $E(n)$ is NS and $\triangle E(n) P B$, then $D$ is NS.

If $E(n)$ is $Z$ and $\triangle E(n) N B$, then $D$ is NS.

If $E(n)$ is $Z$ and $\Delta E(n) N S$, then $D$ is $Z$.

If $E(n)$ is $Z$ and $\Delta E(n) Z$, then $D$ is $Z$.

If $E(n)$ is $Z$ and $\triangle E$ (n) $P S$, then $D$ is $Z$.

If $E(n)$ is $Z$ and $\triangle E(n) P B$, then $D$ is $P S$.

If $E(n)$ is $P S$ and $\triangle E(n) N B$, then $D$ is $P S$.

If $E(n)$ is $P S$ and $\triangle E$ (n) NS, then $D$ is PS.

If $E(n)$ is $P S$ and $\Delta E(n) Z$, then $D$ is $P S$.

If $E(n)$ is $P S$ and $\triangle E(n) P S$, then $D$ is $Z$.

If $E(n)$ is $P S$ and $\triangle E(n) P B$, then $D$ is $Z$.

If $E(n)$ is $P B$ and $\triangle E(n) N B$, then $D$ is $P B$.

If $E(n)$ is $P B$ and $\triangle E(n) N S$, then $D$ is $P B$.

If $E(n)$ is $P B$ and $\Delta E(n) Z$, then $D$ is $P B$.

If $E(n)$ is $P B$ and $\triangle E(n) P S$, then $D$ is $Z$.

If $E(n)$ is $P B$ and $\triangle E(n) P B$, then $D$ is $Z$.

Considering any specific rule as for example, (1) when $E$ is NB and $\triangle E$ is NB, it means that $E$ is higher than the voltage around MPP with a small $\triangle E$ in voltage; we directly assign the duty cycle $D$ to be $Z$ for the drive. By using such a medium $D$, it is enough to make the exceeded $E$ decreasing a little back to a suitable value. (2) When $E$ is $Z$ and $\Delta E$ is $Z$, it means that $E$ and $\triangle E$ are at the medium values in the full range, i.e. $E$ is lower than the voltage on MPP. Then, we have to assign the duty cycle $D$ to be $Z$ for the medium drive. 
c) Defuzzification method: Defuzzification is the aggregation of the $D$ from all rules, i.e. the duty cycles from 25 rules must be computed and combined for a specified crisp value of output. Defuzzification method gives a quantitative summary, i.e. given the possibility distribution of the fuzzy output, defuzzification amounts to selecting a single representative value that captures the essential meaning of the given distribution. The Defuzzification method used for the present case is the centroid method as this is the most prevalent and physically appealing of all the defuzzification methods. It is given by the algebraic expression:

$$
\mathrm{D}=\frac{\sum_{j=1}^{n} \mu(\mathrm{Dj})-\mathrm{Dj}}{\sum_{j=1}^{n} \mu(\mathrm{Dj})}
$$

Where $D$ is the defuzzified value, Union of the membership functions is found by the MAX aggregation method and $\mu(\mathrm{Dj})$ is the degree of the membership function.

The entire process of Implication, Aggregation and Defuzzification of the system is shown in the Rule View window of Fuzzy Logic Toolbox as described by Figure 13 and 14.

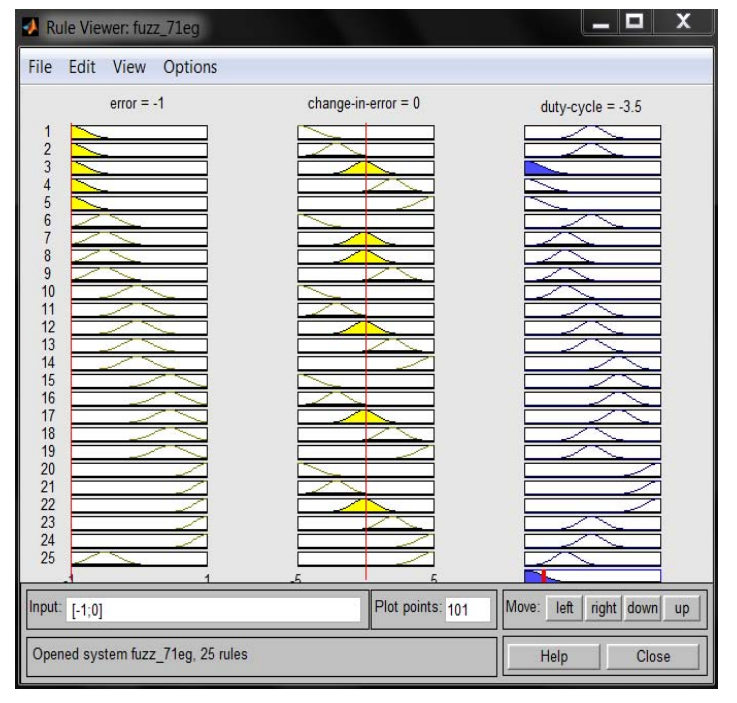

Figure 13. Fuzzy Rule Viewer

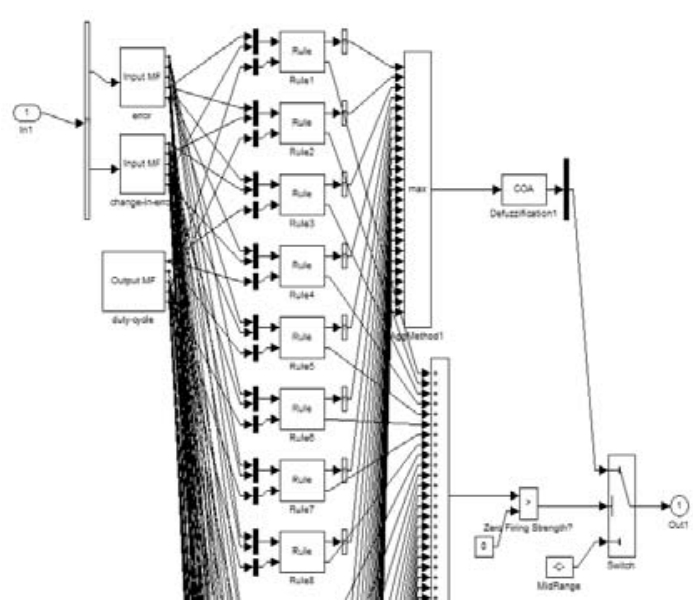

Figure 14. Fuzzy Rule Wizard

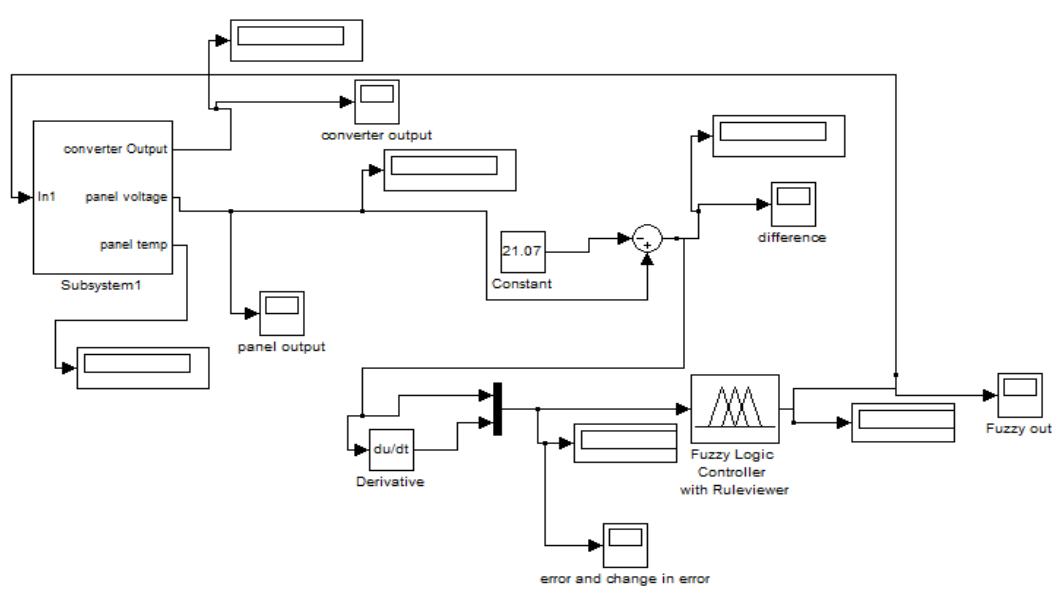

Figure 15 Fuzzy Logic Controller correcting Converter output 
The controller makes feasible decisions for what action is to be taken. The universe of discourse for error input is taken $[-8,+8]$ and change in error is chosen to be $[-10,+10]$ for the panel voltage output and the output variable duty cycle is chosen to be as $[-8,8]$. The range of the input variables can be changed according to the changing demand for the varying input. The Simulink model using FLC is given in Figure 15.

\section{Results}

The system was tested for various subsets of error and change in error with changeable crossover points. The converter outputs using fuzzy are shown in Table 9.

Table 9. FLC controlled output

\begin{tabular}{cc}
\hline Parameter & Set point STC $=21.07 \mathrm{~V}$ \\
& Panel output for variable T=21.86 V \\
\hline Converter Output using FLC & $21.40 \mathrm{~V}$ \\
Duty Cycle & 0.978 \\
\hline
\end{tabular}

It can be seen from the results of Figure above that the output of the system is under control and closer to set point even when the disturbance is added to the system. The model developed in this section shows that it can be easily implemented in the industry.

\section{Conclusion}

The panel characteristics using buck converter are implemented for variable temperature and irradiance monitoring Fuzzy controllers. The duty cycle is also reduced. Buck converters can monitor MPP more closely to STC by using selected membership functions and parameter modeling of FLC. Moreover, less cost for computing and faster response together with satisfactory results for FLC are observed.

\section{Acknowledgements}

Acknowledgements may be made to all those individuals and institutions not mentioned elsewhere in the paper but that made an important contribution.

\section{References}

[1] Energy Statistics Report, Central Statistics Office, National Statistical Organization, Ministry of Statistics and Programme Implementation, Government Of India. 2014.

[2] N Pongratananukul. Analysis and Simulation Tools for Solar Array Power Systems. Ph.D. dissertation. Orlando: Dept. Electrical and Computer Engineering, Univ. Central Florida. 2005.

[3] Chandani Sharma, Anamika Jain. Solar Panel Mathematical Modelling using Simulink. In International Journal of Engineering Research and Applications. 2014; 4(5): 67-72.

[4] Chandani Sharma, Anamika Jain. Simulink based Multivariable Solar Panel Modelling. In Telkominika Indonesian Journal of Electrical Engineering. 2014; 12(8): 5784-5792.

[5] Li Shuhui, A Timothy, Haskew, Li Dawen, Fei Hu. Integrating photovoltaic and power converter characteristics for energy extraction study of solar PV systems. Renewable Energy. 2011; 36(12): 3238-3245.

[6] G Balasubramanian, S Singaravelu. Fuzzy logic controller for the maximum power point tracking in photovoltaic system. International Journal of Computer Applications. 2012; 41(12).

[7] Zadeh LA. Fuzzy sets. Information and Control. 1965; 8: 338-353.

[8] Mamdani EH. Application of fuzzy algorithms for the control of a dynamic plant. Proceedings of IEEE. 1974: $121 ; 1585-1588$.

[9] MA Islam, N Mohammad, PKS Khan. Modeling and performance analysis of a generalized photovoltaic array in Matlab. Joint International Conference on Power Electronics, Drives and Energy Systems by IEEE. 2010.

[10] Yeong-Chau Kuo, Tseng-Jun Liang, Jiang-Fuh Chen. Novel Maximum-Power-Point-Tracking Controller for Photovoltaic Energy Conversion System. IEEE Transactions on Industrial Electronics. $2001 ; 48(3)$. 
[11] Tarak Salmi, Mounir Bouzguenda, Adel Gastli, Ahmed Masmoudi. MATLAB/Simulink Based Modelling Of Solar Photovoltaic Cell. International Journal of Renewable Energy Research. 2012; 2(2).

[12] S Lalouni, D Rekioua, T Rekioua, E Matagne. Fuzzy logic control of stand-alone photovoltaic system with battery storage. Journal of Power Sources 193. 2009: 899-907.

[13] Dr P Sangameswar Raju, Mr G Venkateswarlu. Simscape Model of Photovoltaic cell. International Journal of Advanced Research in Electrical, Electronics and Instrumentation Engineering. 2013; 2(5).

[14] V Salas, E Oli's, A Barrado, A Lazaro. Review of the maximum power point tracking algorithms for stand-alone photovoltaic systems. Solar Energy Materials \& Solar Cells 90. 2006: 1555-1578.

[15] Pavels Suskis, Ilya Galkin. Enhanced Photovoltaic Panel Model for MATLAB-Simulink Environment Considering Solar Cell Junction Capacitance. Industrial Electronics Society, IECON 2013 - 39th Annual Conference of the IEEE. 2013. 